\title{
O PAPEL DAS REPRESENTAÇõES NA TRANSPOSIÇÃO DIDÁTICA DO CONCEITO DE FUNÇÃO
}

\section{DIDACTIC SEQUENCES IN THE TEACHING OF MATHEMATICS: A RESEARCH WITH THE TEACHERS IN THE FINAL SERIES IN RELATION TO THE TOPIC PYTHAGORAS}

\author{
Edson Alkimim, Maria Auxiliadora Vilela Paiva \\ Instituto Federal do Espírito Santo \\ E-mail: ealkimim@gmail.com, vilelapaiva@gmail.com
}

\section{Resumo}

Neste artigo, parte da pesquisa de Mestrado Profissional do Programa de Pós-Graduação Educimat/Ifes, analisamos a construção do conceito de função, apresentado pelo livro didático "Matemática Ciências e Aplicações - Volume 1", de Gelson lezzi... [et al.], baseados nos referenciais teóricos de Yves Chevallard (1991), Raymond Duval $(2011,2012)$ e Bento Jesus Caraça (2010). Partimos do princípio de que um objeto de ensino passa por transformações até se tornar um saber a ser ensinado e que trabalhar as diferentes representações deste objeto e as relações entre essas representações permeiam a construção do conceito a ser trabalhado na escola. Procuramos, então, compreender como o conceito de função foi historicamente construído, refazendo a sua trajetória de produção como conhecimento científico e identificando os elementos necessários para promover a sua representação dentro do processo de transposição didática: de "saber sábio em objeto de ensino" (CHEVALLARD, 1991). Os autores do livro didático analisado não apresentaram elementos fundamentais para formalizar o conceito de função de forma que os alunos dessem significado a esse objeto de ensino, apropriando-se das noções de dependência, correspondência, variáveis dependentes e independentes.

Palavras-chave: transposição didática. representação semiótica. conceito de função. livro didático.

\section{Abstract}

In this article, part of the Professional Master's degree research in the Post Graduate program content from Educimat/Ifes we analyze the development of the function concept, submitted by textbook "Matemática Ciências e Aplicações" - Volume I, written by Gelson Lezzi... [et al.], based on theorical references as Yves Chevallard (1991), Raymond Duval(2011,2012) and Bento Jesus Caraça(2010). We start from the principal that a object of teaching goes to transformation until become a knowledge to be taught, and that work in different representations of this object and the relationships between those representations to be part of the construction of the concept to be worked at school. We seek, then, to understand how the concept of function was historically built, remaking its trajectory production as scientific knowledge and identifying the necessary elements to promote their representation within the didactic transposition process: to "wise knowledge in teaching object" (CHEVALLARD, 1991). The authors from the textbook did not present the key elements to formalize the function concept, in order that the students could provide a 
meaning to this object of teaching, by taking notions of dependence, correspondence, dependent and independent variables.

Palavras-chave: didatic transposition. semiotics representation. concept of function. text book. 


\section{INTRODUÇÃO}

Os saberes de domínio escolar têm, em geral, como parâmetro necessário, os saberes de domínio acadêmicos ou científicos, aceitos pela comunidade científica de uma determinada área de conhecimento, a partir dos quais será feita a transposição didática de conceitos e hipóteses para o contexto de sala de aula. Este é um tema que tem sido pesquisado por vários autores da área da educação e, em particular, do ensino de ciências e matemática. No caso específico da Educação Matemática, temos diversas pesquisas que nos remetem às tendências teóricas da Didática da Matemática provenientes da escola francesa, na qual destacamos Yves Chevallard (1991) e Raymond Duval (2011; 2012). Sobre a teoria da transposição didática, Chevallard (1991) afirma que

Um conteúdo de saber que tenha sido definido como saber a ser ensinado passa, a partir de então, por um processo de transformação fazendo ajustes e adaptações para torná-lo capaz de ocupar um lugar entre os objetos de ensino. O "trabalho" que faz de um objeto de saber a ser ensinado em um objeto de ensino é chamado de transposição didática (p. 39 - tradução nossa) ${ }^{1}$.

Os conceitos matemáticos foram continuamente construídos e evoluídos em diferentes períodos históricos, como ocorreu com o conceito de função. O caminho percorrido por esse conceito, até culminar nas definições conhecidas hoje em dia, só foi possível a partir de um processo histórico, longo e delicado, consequência de estudos acadêmicos e científicos produzidos nas universidades e institutos de pesquisa, resultando em um alto nível de abstração. Ele aparece numa linguagem diferenciada e complexa, não podendo ser aplicada em sala de aula sem as devidas adaptações e problematizações necessárias à realidade do aluno. Assim, é necessário que se faça uso de representações adequadas ao trabalhar esse conceito, de forma a torná-lo acessível ao nível de desenvolvimento cognitivo dos alunos.

1 Un contenu de savoir ayant été designé comme savoir à enseigner subit dès lors un ensemble de transformations adaptatives qui vont le rendre apte à prendre place parmi les objets d'enseignement. Le "travil" qui d'un objet de savoir à enseigner fait un objet d'ensignement est appel é la transposition didactique. 
Nesse sentido, a linguagem usada no livro didático para a introdução de um determinado conceito é um componente que interfere diretamente no processo de ensino-aprendizagem, por ser um material didático de grande influência na educação, conforme indicam diversas pesquisas Brasileiras. Sabe-se que, na maioria dos casos, ele é a única fonte de referência com que o professor de matemática conta para organizar as suas aulas e, até mesmo, firmar seus conhecimentos, bem como a única fonte científica de pesquisa para alguns alunos. Contudo, para o ensino de um determinado saber escolar para alunos da educação básica, o autor do livro não deve abusar de linguagens formais antes de propor uma construção inicial do objeto de estudo. No caso do conceito de função, ao mesmo tempo em que sua apresentação nos livros deve manter o rigor de seus conceitos fundamentais, de acordo com Bento Jesus Caraça (2010), é necessário que sofra algumas transformações e adaptações, passando pela transposição didática defendida por Yves Chevallard (1991), processo no qual se encontra o sistema de representação semiótica de Raymond Duval (2011 e 2012). A utilização de um sistema de representação do objeto matemático está diretamente ligada ao processo de transposição didática, pois a forma que o autor escolhe para representar um determinado conceito no livro passa pela escolha de códigos, símbolos, gráficos, tabelas, etc.

Com o objetivo de entendermos como a transposição didática do conceito de função se deu no livro didático "Matemática Ciências e Aplicações - Volume 1", de Gelson lezzi... [et al.] (2010), desenvolvemos uma pesquisa de natureza qualitativa, analisando as representações com que os autores desse livro propuseram trabalhar o conceito de função nas atividades apresentadas. Para tanto, procuramos identificar: como ocorreu a organização desse conteúdo e os métodos adotados para que os alunos possam aprendê-lo; se nessas propostas os autores contemplaram as três atividades cognitivas fundamentais à produção de significados de um sistema de representação, a saber: "a formação de uma representação identificável, o tratamento e a conversão de uma representação" (DUVAL, 2012); e se os principais elementos da definição desse conceito sofreram adequadamente as transformações necessárias para uma aprendizagem efetiva. 
A forma como os autores de livros didáticos representam os conteúdos é de extrema importância para a apreensão desse conceito, o que dá a esse material um papel relevante na transformação de saber a ensinar em saber ensinado, com a finalidade de favorecer o planejamento e a aprendizagem dos alunos. De acordo com o PNLD $2012^{2}$, nesse processo

[...] a sala de aula constitui-se em um cenário no qual se estabelecem interrelações entre o professor, o aluno, o livro didático e os saberes disciplinares. O livro didático traz para o processo de ensino e aprendizagem um personagem, o seu autor, que passa a dialogar com o professor e com o aluno. Nesse diálogo, o livro é portador de escolhas sobre: o saber a ser estudado; os métodos adotados para que o aluno consiga aprendê-lo mais eficazmente; e a organização dos conteúdos ao longo dos anos de escolaridade (BRASIL, $2011^{3}$, p. 12-13).

Os fracassos do processo de ensino-aprendizagem do conceito de função não podem ser atribuídos, simplesmente, pelas deformidades do uso de símbolos e linguagens na sua representação. Entretanto, dentro da didática da matemática, não se pode negar as relações existentes entre o sujeito que adquire um conhecimento e as representações que expressam o objeto matemático de estudo. Dentro da realidade escolar, não se pode desprezar as influências que são passadas pela linguagem empregada pelo professor e pelo autor do livro didático adotado como elementos mediadores entre o aluno e o conhecimento.

\section{ANÁLISE HISTÓRICA DO CONCEITO DE FUNÇÃO: trajetória de produção como saber} sábio

O saber matemático formalizado na forma que conhecemos e apresentado em sala de aula

2 2012: ano no qual iniciou-se o triênio para utilização dos livros avaliados pelo Programa Nacional do Livro Didático - PNLD. Este Programa tem como principal objetivo subsidiar o trabalho pedagógico dos professores, por meio da distribuição de coleções de livros didáticos aos alunos da educação básica.

3 2011: ano no qual foram realizadas as avaliações das obras e publicado, pelo MEC, os documentos com as recomendações de escolha pelas escolas. Este trabalho sempre ocorre no ano anterior ao ano que se inicia a utilização dos livros. 
advém de um processo longo de construção, que ocorreu concomitantemente à própria história da humanidade, sofrendo, ao longo dessa trajetória, transformações, deformações e distorções até chegar à forma pelo qual se apresenta em nossos dias. O conceito de função, historicamente, sempre se apresentou com certa relevância na formação das ciências e, principalmente, da matemática, ligado a situações que envolvem abstrações, interpretações e resolução de problemas, destacando-se como uma ferramenta de relevância na produção científica e construção social. Esse conceito sempre esteve presente em diversas situações do dia a dia, não se limitando somente a cálculos numéricos. Antes da discussão quantitativa de função, sempre existiram leis do tipo funcionais que definiam interdependências na natureza. Caraça (2010) chama-nos a atenção para que

Olhemos, por exemplo, coisa tão simples como o crescimento duma pequena erva num campo, e examinemos, com cuidado, as coisas de que depende: temos, em primeiro lugar, a constituição geológica do solo, a quantidade de calor recebida do sol, etc., [...] sobre o crescimento da pequena planta influem as condições climáticas da região, e estas dependem de toda a complexidade de fenômenos atmosféricos e marinhos, atividades das manchas solares, etc.. [...] Como se vê, uma vez examinada a questão com um pouco de cuidado, começam a aparecer as dependências, a ligar-se os problemas; - problemas cosmológicos, problemas físicos, problemas econômicos, problemas sociais, tocam-se e entrelaçam-se no mais íntimo detalhe do organismo universal (p. 103).

De forma "filosófica", Caraça (2010) nos mostra que as interdependências entre os conjuntos de relações entre seres e fatos sempre existiram. Pode-se, desta forma, afirmar que o conceito de função aparece a partir da conjunção de estudos qualitativos e quantitativos dos "fenômenos naturais". "Fenômenos naturais são, portanto, o movimento dos corpos, a vaporização da água sob a ação do calor, a passagem duma corrente elétrica num condutor, a germinação duma semente, o exercício de direitos políticos pelos cidadãos etc." (CARAÇA, 2010, p. 112). Um cientista, ao investigar e descrever as regularidades de um fenômeno 
natural, estará descrevendo as leis de sua evolução.

Estudar essas regularidades, desde a Pré-história, já era fundamental para a previsão e o domínio da Natureza. Os homens já faziam investigações e previsões, definindo leis de variações de qualidades e quantidades, o que nos leva a crer que, intuitivamente, já existiam relações funcionais entre os seres e os fatos daquela época. Para controlar rebanhos e ter certeza de que nenhum animal havia fugido ou morto por predadores, os homens da antiguidade usavam pedras fazendo uma relação biunívoca entre o conjunto de pedras e a quantidade de animais do rebanho. Assim, relacionando objetos com outros objetos, o homem começa a desenvolver a noção de função.

Portanto, podemos enumerar em quatro as principais etapas do desenvolvimento da noção de função. (0) a Pré-história, que marcamos como a primeira ou "marco zero" delas, além de outras três etapas desse desenvolvimento, de acordo com a classificação devida à Youschkevitch (1981, p. 9):

(1) A Antiguidade: etapa na qual o estudo de casos individuais de dependência entre duas quantidades ainda não isolou os conceitos básicos de quantidades e funções variáveis (tradução nossa).

(2) A Idade Média: etapa na qual, na ciência europeia do século XIV, essas noções são, pela primeira vez e de forma precisa, expressas simultaneamente na forma geométrica e mecânica, entretanto na antiguidade, cada caso concreto de dependência entre duas quantidades era definido por uma descrição verbal ou por um gráfico, em vez de uma fórmula (tradução nossa).

(3) O período moderno: etapa na qual, a partir do fim do século XVI e especialmente durante o século XVII, as expressões analíticas de funções

4 (1) L'Antiquité: étape au cours de laquelle l'étude des différents cas de dépendance entre deux quantités n'a pas encore isolé les notions générales de quantités variables et de fonctions.

5 (2) Le Moyen-Age: étape au cours de laquelle, dans la science européenne du 14e siècle, ces notions sont pour la première fois et d'une manière précise exprimées à la fois sous une forme géométrique et mécanique, mais pendant laquelle, comme dans l'antiquité, chaque cas concret de dépendance entre deux quantités est défini par une description verbale ou par un graphe plutôt que par une formule. 
começam a prevalecer; a classe das funções analíticas, geralmente, é expressa por meio de soma de séries infinitas, tomando-se logo a principal classe utilizada (tradução nossa) .

$\mathrm{Na}$ Antiguidade, entre os babilônios, em 2000 anos a.C., conforme relatado por Oliveira (1997), já existiam tabelas sexagesimais. Segundo a autora, a estas tabelas podem ser atribuídas uma funcionalidade, pois uma função tem sido definida como uma tabela de correspondência. Os egípcios, assim como os babilônios, também construíram tabelas para representar correspondência. Oliveira (1997) afirma que

Apesar de tais tabelas indicarem a presença das dependências funcionais na época, "não havia nenhuma ideia geral de funcionalidade na Antiguidade" (YOUSCHKEVITCH 1981, p. 13) ${ }^{7}$. Portanto, o pensamento matemático da Antiguidade não criou nenhuma noção geral nem de quantidade variável nem de função (p. 15 - tradução do autor).

Na Idade Média, conforme nos aponta Oliveira (1997), a primeira vez que a noção de função aparece numa forma "mais genérica" foi no século XII, quando alguns matemáticos estudaram fenômenos como o calor, a luz, a cor, a densidade, a distância, a velocidade, etc. Simultaneamente, a ideia de que as leis quantitativas da natureza eram leis do tipo funcional amadurecia, pouco a pouco, na "Filosofia Natural".

O período moderno foi, então, caracterizado pelos experimentos de Galileu (1564-1642) que, por meio de instrumentos de medida, introduziu o quantitativo nas representações gráficas, lidando, de forma funcional, com as causas e efeitos de suas experiências, como no caso do

6 (3) La période moderne: au cours de laquelle, à partir de la fin du 16e siècle et spécialement pendant le 17e siècle, les expressions analytiques de fonctions commencent à prévaloir ; la classe des fonctions analytiques, généralement exprimées au moyen de sommes de séries infinies, devenant bientôt la principale classe utilisée.

7 n'y avait aucune idée générale de fonctionnalité dans l'Antiquité.

8 FILHO \& SILVA (2006) afirmam que, denominada por Aristóteles, a Filosofia Natural é a parte da filosofia que trata do conhecimento das primeiras causas e dos princípios do mundo material. Diversamente das disciplinas científicas (ciência), não busca uma descrição dos fenômenos da natureza, mas procura chegar à essência dos entes que possuem corpo e tem por objeto formal o ser das coisas corpóreas. 
movimento (velocidade, aceleração e distância percorrida), que foi o principal campo estudado por ele. No entanto, segundo Oliveira (1997), a generalização de quantidades explicitadas por uma expressão geral surgiu em princípios do século XVI. Nesta época, François Viète (1540-1603) usava "consoantes" para representar parâmetros e "vogais" para representar variáveis, distinguindo, por meio desta "álgebra simbólica", quantidades dadas de quantidades desconhecidas, em substituição à "álgebra retórica" que era, até então, apresentada em linguagem corrente. Segundo Youschkevitch (1981),

\begin{abstract}
A importância desta notação que, pela primeira vez, tornou possível colocar por escrito uma forma simbólica das equações algébricas e expressões contendo quantidades desconhecidas e coeficientes arbitrários (um trabalho que também nasceu com VIÈTE) pode ser superestimada. No entanto, o criador da nova Álgebra não usou sua notável descoberta para "levar adiante" o conceito de função: pensar em termos de função não era característica de sua mente (p. 23- tradução nossa) ${ }^{9}$.
\end{abstract}

Encontramos, em Youschkevitch (1981), a definição explícita de uma função como uma expressão geral dada por Bernoulli (1667-1748), em um artigo publicado em "Memórias da Academia Real de Ciências de Paris", em 1718: "Chamamos a função de uma grandeza variável composta de qualquer forma dessa grandeza variável e constante" (YOUSCHKEVITCH, 1981, p. 35 - tradução nossa) $)^{10}$; Dirichlet (1805-1859) quebra a forma antes comportada da definição de função e fornece uma definição considerada ampla, que se aproxima da noção moderna de correspondência. Segundo ele,

Se uma variável $y$ está relacionada com uma variável $x$ de tal modo que, sempre que é dado um valor numérico a $x$, existe uma regra segundo a qual

9 L'importance de cette notation qui, pour la première fois, a rendu possible la mise par écrit sous une forme symbolique des équations algébriques et des expressions contenant des quantités inconnues et des coefficients arbitraires (un travail prenant aussi naissance avec VIETE) pourrait être surestimés. Cependant le créateur de l'Algèbre nouvelle n'utilisa pas sa remarquable découverte pour "faire avancer" le concept de fonction : penser en terme de fonction ne fut pas caractéristique de son esprit.

10 On appelle fonction d'une grandeur variable une quantité composée de quelque manière que ce soit de cette grandeur variable et de constantes. 
um valor único de y fica determinado, então diz-se que $y$ é função da variável independente $x$ "' (BOYER, 1974, p. 405).

Ao nos reportarmos às definições atribuídas à função no século XX, encontramos em Mendes (1994) outras referências que mostram a definição de função como relação entre conjuntos. Do Grupo Bourbaki:

Sejam $E$ e $F$ dois conjuntos, distintos ou não. Uma relação entre uma variável $x$ de $E$ e uma variável $y$ de $F$ é dita uma relação funcional em $y$, ou relação funcional de $E$ em $F$, se qualquer que seja $x \in E$, existe um e somente um elemento $y \in F$ que esteja associado a $x$ na relação considerada [...]. Dáse o nome de função à operação que desta forma associa a todo elemento $x$ $\in E$ o elemento $y \in F$ que se encontra ligado a $x$ na relação dada; diz-se que $y$ é o valor da função para o elemento $x$, e que a função está determinada pela relação funcional considerada. (MENDES, 1994, p. 53).

Partindo em busca de um instrumento matemático para estudo de leis quantitativas, Caraça (2010) simula condições físicas necessárias e um isolado conveniente, induzindo-nos à procura de "regularidades" de fenômenos: "as leis quantitativas". Ele dá uma noção do "conceito de variável" como ideia fundamental daquele instrumento procurado: "Seja $E$ um conjunto qualquer de números, conjunto finito ou infinito, e convencionemos representar qualquer dos seus elementos por símbolo, por ex.: $x$. A este símbolo, representativo de qualquer dos elementos do conjunto $E$, chamamos variável" (CARAÇA, 2010, p. 119-120). Quando Caraça (2010) reduz o conjunto $E$ a um intervalo do conjunto dos números reais, e $x$ a sua "variável", isto significa que "o símbolo $x$, sem coincidir individualmente com nenhum dos números reais desse intervalo, é susceptível de representá-los a todos; é, afinal, o símbolo da vida coletiva do conjunto, vida essa que se nutre da vida individual de cada um dos seus membros, mas não se reduz a ela" (CARAÇA, 2010, p. 120).

Não nos falta mais uma generalização conveniente por meio de uma representação simbólica 
para esse objeto matemático. Passa-se a generalizar os resultados da função $y=f(x)$, na qual à variável $x$ ele chama de "variável independente" e à variável y de "variável dependente". Quando Caraça (2010) diz que $y=f(x)$, ele afirma que em qualquer valor de $x$ corresponde a um único valor de $y$. Resumindo seu conceito de função, Caraça (2010) dá uma definição:

Sejam $x$ e $y$ duas variáveis representativas de conjuntos de números; diz-se que $y$ é função de $x$ e escreve-se (1) $y=f(x)$, se entre as duas variáveis existe uma correspondência unívoca no sentido $x \rightarrow y$. A $x$ chama-se variável independente, a y variável dependente (p. 121).

\section{A REPRESENTAÇÃO SEMIÓTICA NA TRANSPOSIÇÃO DIDÁTICA DO CONCEITO DE FUNÇÃO}

A compreensão de um conceito matemático por um aluno só é possível por meio do entendimento de expressões e linguagens matemáticas a que ele terá contato, seja na escola ou por interferência de algum outro sujeito escolarizado, para promover transformações e adaptações de um determinado saber definido como saber a ensinar, para ocupar um lugar entre os objetos de ensino. Trata-se, assim, da transposição didática de Chevallard (1991) e do sistema de representação semiótica de Duval (2012), que aparecem nos resultados dos planejamentos e dos atos pedagógicos do professor em sala de aula.

De fato, os objetos matemáticos não estão diretamente acessíveis à percepção ou à experiência intuitiva imediata, como são os objetos comumente ditos "reais" ou "físicos". É preciso, portanto, dar representantes. E por outro lado, a possibilidade de efetuar tratamentos sobre os objetos matemáticos depende diretamente do sistema de representação semiótico utilizado (DUVAL, 2012, p.268).

Para se ensinar um determinado objeto de saber, faz-se necessária sua modificação, deixando-o mais acessível para sua apropriação. Esta modificação, alvo de vários estudos, denomina-se "transposição didática", segundo Chevallard (1991). A transposição ocorre nas 
deformações que um determinado saber de domínio acadêmico sofre até se tornar em conteúdos propostos nos currículos e livros didáticos e, a partir destes, quando são selecionados pelo professor de acordo com o que considera relevante, de forma a constituir competências na sua proposta pedagógica.

Conforme Chevallard (1991), o conhecimento passa por, pelo menos, três tipos distintos de transformações: o conhecimento como saber sábio, saber a ensinar e saber ensinado ${ }^{11}$. 0 saber sábio é aquele produzido nas academias por meio de um conjunto de regras específicas de produção de conhecimentos, as quais consistem em juntar evidências reais baseadas na verificação e observação sistemática, controladas e analisadas com o uso da lógica da ciência. Trata-se de um conhecimento apurado, advindo de uma atividade criteriosa, que segue um método de investigação, em que, por meio da observação da experiência, coletam-se dados a fim de se montar uma hipótese para explicar um fenômeno.

O saber a ensinar trata-se da transposição didática de um determinado saber sábio. Esse processo transpositivo ocorre em uma noosfera e depende, diretamente, das influências externas que o saber sofre na sua trajetória, contribuindo para uma redefinição de conceitos e para a reformulação de sua apresentação. Leite (2004) afirma que esta influência é exercida por uma interface entre o saber e os especialistas de educação, as políticas públicas, os autores de livros e o entorno social, evidenciando uma inserção da representação do sistema de ensino na sociedade. As influências dessa noosfera, responsável pela transposição didática externa, resulta não só na escolha de conteúdos como também na definição de objetivos, métodos e valores que conduzem o sistema de ensino. A noosfera seria responsável, no plano do saber, por viabilizar a compatibilidade entre o sistema de ensino, o contexto social e seu entorno. O saber sábio se materializa na forma de currículo, livros didáticos, programas e materiais institucionais de apoio ao professor.

Esse movimento realizado pela noosfera acaba por não atender a todos os elementos necessários às condições didático-metodológicas. Sendo assim, para que seja possível 11 Savoir Savant, savoir à ensigner et savoir ensigné (CHEVALLARD, 1991). 
ensinar um determinado objeto matemático, a partir do saber a ensinar, é necessário que o professor, por meio do planejamento, dê a ele as diversas representações necessárias para sua compreensão (DUVAL, 2011 e 2012). O que reforça a importância de uma nova transposição didática do saber a ensinar que passa pelo fazer em sala de aula nos remetendo ao saber ensinado.

O saber ensinado é o resultado da transformação dos conteúdos definidos pelos programas de ensino, mediante adaptação e organização por meio das diversas representações pertinentes. Conforme Chevallard (1991), "quando os programas são preparados, assinado e se tornam lei, começa outro trabalho: a transposição didática interna" (p. 37 - tradução nossa) $)^{12}$. Nesse cenário, o professor é visto como um dos principais personagens desta transformação, uma vez que cabe a ele, para melhor compreensão por parte dos alunos, adequar o saber a ensinar apresentados nos currículos e livros didáticos em conhecimentos a serem discutidos e trabalhados em sala de aula. Assim, para uma boa compreensão de um conceito matemático, é necessário, portanto, que o professor dê a ele suas diversas representações. A transposição didática dos objetos matemáticos depende, diretamente, do sistema de representação semiótico utilizado pelo professor. "As representações semióticas desempenham um papel fundamental na atividade matemática" (DUVAL, 2012, p. 268).

Segundo Duval (2012), a apreensão de um objeto matemático, por meio de um registro de representação, parte de três atividades cognitivas fundamentais, a saber: a formação de uma representação identificável; o tratamento de uma representação; e a transformação de uma representação de um registro para outro, ou seja, a conversão. A representação de um registro é a essência na comunicação do que se quer expressar acerca do objeto de estudo. $A$ preocupação central desta teoria está nas atribuições e significações que o aluno confere a partir de suas construções mentais do objeto matemático representado. Duval (2012) aborda tais construções como "representações mentais" que o aluno passa a atribuir, ou que já atribuía, a um determinado objeto matemático que os alunos tiveram acesso em etapas de estudos anteriores. Este autor afirma, ainda, que as representações mentais e as 12 Lorsque les programmes sont préparés trouver un autre emploi: la transposition didactique interne. 
representações semióticas trabalham uma ao lado da outra, pois o desenvolvimento das representações mentais se efetua como uma interiorização das representações semióticas, da mesma forma que as imagens mentais são uma interiorização de sua observação. 0 domínio de conceitos matemáticos, como no caso do conceito de função, depende das representações semióticas usadas para complementar as representações mentais que o aluno faz sobre tais objetos. Conforme Duval (2012)

As representações mentais recobrem o conjunto de imagens e, mais globalmente, as conceitualizações que um indivíduo pode ter sobre um objeto, sobre uma situação e sobre o que the é associado. As representações semióticas são produções constituídas pelo emprego de signos pertencentes a um sistema de representações que tem inconvenientes próprios de significação e de funcionamento. Uma figura geométrica, um enunciado em língua natural, uma fórmula algébrica, um gráfico são representações semióticas que exibem sistemas semióticos diferentes (p. 269).

A linguagem usada para a representação do conceito de função é um componente que interfere diretamente na sua compreensão. Ao ensinarmos conceito de função a alunos do ensino básico, é necessário propor várias representações para que eles estabeleçam uma representação mental desse objeto matemático e possam dar-lhe significado. Na passagem do saber a ensinar para o saber ensinado no ensino desse conceito, a formalização precipitada de códigos, símbolos e linguagens carregadas, possivelmente se constituirá em mais uma dificuldade de aprendizagem para o aluno. O que se quer dizer é que o uso de determinado sistema de signos, sinais e palavras escritas e faladas etc., associados a um conjunto de regras de manipulação dos mesmos, depende diretamente da sua transposição didática.

O caminho percorrido pelo conceito de função até culminar nas definições de Dirichlet e do Grupo Bourbaki, só foi possível a partir de um processo longo e delicado, resultando em um 
alto nível de abstração desse conceito, ampliando-o para conjuntos de objetos matemáticos antes pouco imagináveis. Esse nível superior de abstração que o conceito de função alcançou é, por consequência, um saber de nível acadêmico ou científico, produzido nas universidades e institutos de pesquisa. Possui uma linguagem bem diferenciada e elaborada que, se desta forma for aplicada no ensino médio sem as devidas adaptações e problematizações, poderá não alcançar as representações que o aluno já possui deste objeto matemático, constituindose em mais um obstáculo na sua aprendizagem. Na linguagem matemática, usada para o ensino do conceito de função, devemos englobar todos os signos possíveis, de forma a promover atividades cognitivas no sujeito, fazendo o seu tratamento e conversão para propiciar, ao aluno, uma boa representação mental deste objeto matemático, ou seja, contribuir na construção do conceito.

Nos sistemas de signos escolhidos para o ensino do conceito de função devem estar incluídas as linguagens algébricas formais utilizadas na sua demonstração e definição, além de gráficos, tabelas, desenhos e linguagem natural (escrita e falada). Trata-se da conversão de uma representação, ou seja, fazer uma "transformação desta função em uma interpretação em outros registros, conservando a totalidade ou uma parte somente do conteúdo da representação inicial" (DUVAL, 2012, p. 272 - grifo do autor). Essa conversão aparece também na teoria da transposição didática de Chevallard (1991), o qual afirma que o saber ensinado "deve ser visto como suficientemente próximo do saber sábio, de modo a não incorrer na desaprovação de matemáticos, minando a legitimidade do projeto socialmente aceito e apoiado para seu ensino" (CHEVALLARD, 1991, p. 26 - tradução nossa) ${ }^{13}$.

Observa-se, assim, que a utilização de diferentes sistemas semióticos está diretamente ligada ao conceito de transposição didática de Chevallard (1991). Para ensinar o conceito de função para alunos de primeiro ano do ensino médio, é necessário que suas representações passem por transformações, passem pelas diversas representações. Temos aqui um dos grandes

13 doit être vu, par les "savants» eux-mêmes, comme suffisamment proche du savoir savant, afin de ne pas encourir le désaveu des mathématiciens, qui minerait la légitimité du projet social, socialement accepté et soutenu, de son enseignement. 
problemas da educação matemática: dimensionar o objeto de ensino, fazer transformações e adaptações, de tal forma que atinja o objetivo de estudo, ou seja, deixar o objeto de ensino numa representação semiótica acessível e que atinja as representações mentais que seus alunos já tenham dele. "A distinção entre um objeto e sua representação é, portanto, um ponto estratégico para a compreensão da matemática" (DUVAL, 2012, p. 268).

\section{ANÁlISE DA ABORDAGEM DO CONCEITO DE FUNÇÃO NO LIVRO DIDÁTICO "MATEMÁTICA CIÊNCIAS E APLICAÇÕES - VOLUME I"}

A forma como o professor aborda os conteúdos matemáticos em sala de aula para alunos do ensino médio é, geralmente, a grande responsável para firmar conceitos inicialmente introduzidos a este público em séries anteriores. Também é importante a forma como os autores do livro didático expõem os conteúdos em suas obras, pois dá ao professor, muitas vezes, a segurança de estar de posse de um grande aliado para o bom desenvolvimento do processo ensino-aprendizagem. Portanto, são necessários livros didáticos que abordem os conceitos matemáticos, promovendo conexões com outras áreas do conhecimento com certa coerência entre exemplos, exercícios e as diversas representações de forma que os alunos possam fazer conexões entre elas e estabelecer processos cognitivos da construção do conceito, dando significado ao objeto matemático de estudo.

No livro didático "Matemática: Ciências e Aplicações - Volume 1" de Gelson lezzi [et al.] (2010), observa-se que os autores iniciam a apresentação do conceito de função com o uso de diversos exercícios de aplicação do conteúdo dentro de uma proposta de abordagem contextualizada e envolvendo outras áreas de conhecimento. Apresentam uma grande quantidade de atividades com exemplos resolvidos, exercícios com situações problemas do cotidiano, exercícios complementares, testes de vestibular, desafios com atividades lúdicas e curiosas, que estimulam a criatividade e aplicação de conhecimentos matemáticos na sua resolução. Nessas atividades, por vezes, solicitam que os alunos façam tabela, em outras dão a tabela pronta. Neste ponto, Caraça (2010) deixa claro que tabelas fornecem, simplesmente, 
uma "primeira noção da lei quantitativo-qualitativa" representando correspondência. Ele afirma ainda que

[...] não é, evidentemente, nesta simples tabela que se encontra toda a regularidade [...], mas ela dá uma primeira ideia dessa lei. Em que consiste, no fundo, esta tabela? Em duas sucessões, dois conjuntos, de números [...] postos em correspondência um com o outro, correspondência essa da qual podemos afirmar que é unívoca (CARAÇA, 2010, p. 119).

Conforme esse autor, são as "expressões analíticas" que dão uma "noção de regularidade". Essas aparecem no livro analisado como leis, fórmulas ou expressões algébricas. $O$ trabalho de generalização é que propicia aos alunos a oportunidade de investigação de regularidades de diversos fenômenos matemáticos. Ao representarmos um gráfico de uma função por meio de tabelas estaremos abordando somente um dos três tratamentos de representação gráfica, de acordo com Duval (2011): a "abordagem ponto a ponto".

É por meio desta abordagem que são introduzidas e definidas as representações gráficas. Em referência aos dois eixos graduados, um par de números permite identificar um ponto (e, inversamente, um ponto se traduz por um par de números). Este modo associativo limita-se a alguns valores particulares e aos pontos marcados no plano referencial (DUVAL, 2011, p. 98).

Nos primeiros capítulos do livro didático, os autores apresentaram estudos dos números reais, de conjuntos e suas operações como pré-requisito para o ensino de função, haja vista que, nos capítulos seguintes, que tratam especificamente de função, apresentam a noção deste conceito como relação entre dois conjuntos. Vejamos as definições apresentadas pelos autores:

Dados dois conjuntos não vazios $A$ e $B$, uma relação (ou correspondência) que associa a cada elemento $x \in A$ um único elemento $y \in B$ recebe o nome 
de função de A em B. [...] De modo geral, se $f$ é um conjunto de pares ordenados $(x, y)$ que caracteriza uma função de $A$ em $B$, indicamos $f: A \rightarrow B$. Se nessa função, $y \in B$ é imagem de $x \in A$, indicamos $y=f(x)$ (IEZZI et al., 2010, p. 47-48, grifo dos autores).

Usar relação entre conjuntos para definir função, resulta numa concepção abstrata e improdutiva, se direcionado à modelagem de resolução de problemas. Nela não enfatizam a noção do conceito de função e suas leis de correspondência e de dependência entre duas variáveis, bem como suas aplicações sociais. Neste caso, a definição acima citada substitui o tratamento teórico formal de forma correta, sem dúvidas, mas sem motivação para aplicações relevantes no cotidiano do aluno. Vimos que no século XX o Grupo Bourbaki definiu o conceito de função usando relação entre conjuntos, porém, complementam tal relação funcional por meio de uma "operação" (lei ou regra) de correspondência e de dependência. Ao reportamos neste artigo às definições atribuídas a esse conceito naquele período, citamos tal definição:

Sejam $E$ e $F$ dois conjuntos, distintos ou não. Uma relação entre uma variável $x$ de $E$ e uma variável $y$ de $F$ é dita uma relação funcional em $y$, ou relação funcional de $E$ em $F$, se qualquer que seja $x \in E$, existe um e somente um elemento $y \in F$ que esteja associado a $x$ na relação considerada [...]. Dáse o nome de função à operação que desta forma associa a todo elemento $x$ $\in E$ o elemento $y \in F$ que se encontra ligado a $x$ na relação dada; diz-se que $y$ é o valor da função para o elemento $x$, e que a função está determinada pela relação funcional considerada. (MENDES, 1994, p. 53).

Desde o princípio do capítulo que trata de funções, os autores do livro didático estabelecem relações de grandezas sem defini-la previamente, demonstrando quando uma grandeza está em função de outra, sem dar ao aluno uma definição formal e a representação rigorosa desse conceito. Conforme Chevallard (1991) e Duval (2012), é necessário transformar a representação inicial de uma função em outras representações que a deixe mais acessível, porém deve-se conservar a totalidade ou parte do conceito inicial, ou seja, o saber ensinado 
deve estar suficientemente próximo do saber sábio, de forma a não invalidar a representação inicial socialmente aceita e apoiada para seu ensino. Assim, ao estudarmos qualquer objeto matemático, é essencial não excluirmos a rigorosidade dos conceitos, porém dentro de uma linguagem acessível. Mantendo a rigorosidade desse conceito, estaremos proporcionando aos alunos o ponto de partida para a percepção de hipóteses e teoremas, que são extremamente importantes para que eles consigam prever comportamentos de diversos fenômenos do cotidiano e de outras áreas de conhecimento.

Da mesma forma, os autores definem o "conjunto domínio, contradomínio e imagem da f", sem que os alunos possam estabelecer conexões entre esses conceitos com as representações que conhecem ou que construíram naturalmente: "seja $f: A \rightarrow B$ uma função. O conjunto $A$ é chamado domínio de $f$, e o conjunto $B$ é chamado contradomínio de $f^{\prime \prime}$ (IEZZI [et al.], 2010, p. 51, grifo dos autores). Em seguida, abordam casos particulares por meio de diagramas de flechas, não permitindo generalizações. De acordo com Duval (2012), o domínio de conceitos depende das representações usadas para complementar as representações mentais que o aluno possui dos objetos matemáticos. A representação gráfica pode ser usada, nesse caso, como ponto de partida para estabelecer essa conexão. Em uma representação gráfica de uma função afim, $f: R \rightarrow R$ definida por um determinado intervalo ou "conjunto domínio" no eixo das abscissas, por meio desse gráfico pode ser estabelecido de forma natural o "conjunto contra domínio" no eixo das ordenadas. Complementando, se escolhermos qualquer $x_{1}$ desse domínio, fica fácil vermos que $y_{2}$ é a "imagem da f" e pertence ao contradomínio.

Procurando não incorrer no erro de apresentar a matemática como um conhecimento pronto, acabado, sem vida e fora do contexto, em um único momento histórico de função, os autores fazem uma menção mínima do desenvolvimento desse conceito, resgatando a introdução das palavras função, constante e variável pelo matemático alemão Leibniz (16461716), da notação $f(x)$ pelo suíço Euler e da definição de função dada pelo alemão Dirichlet (1805-1859), que é a mais próxima da definição usada no próprio livro didático. Por fim, 
citam a criação da teoria dos conjuntos no fim do século XIX, a partir da qual foi possível definir função como um conjunto de pares ordenados. No documento "Orientações curriculares para o ensino médio" do Ministério da Educação afirma que

A utilização da História da Matemática em sala de aula também pode ser vista como um elemento importante no processo de atribuição de significados aos conceitos matemáticos. É importante, porém, que esse recurso não fique limitado à descrição de fatos ocorridos no passado ou à apresentação de biografias de matemáticos famosos (BRASIL: 2006, p. 86).

Os autores dão uma noção básica de plano cartesiano e a construção do gráfico de uma função, conhecendo a sua lei de correspondência $y=f(x)$ e seu domínio $D$ finito. Aborda, ainda, que "quando o conjunto $D$ não é finito, podemos construir uma tabela e obter alguns pontos do gráfico; entretanto, o gráfico da função será construído por infinitos pontos" (IEZZI [et al.], 2010, p. 58), estendendo, de forma mínima, o domínio para o conjunto dos números reais. Em seguida, em exercícios propostos, apresentam gráficos solicitando que os alunos identifiquem e expliquem quais deles representam "funções de domínio real". Desde o início do capítulo, os autores apresentaram tal conceito somente por meio de teoria de conjuntos e construção de gráficos por meio de uma "abordagem ponto a ponto". Por essa abordagem

[...] são introduzidas e definidas as representações gráficas. Em referência aos dois eixos graduados, um par de números permite identificar um ponto (e, inversamente, um ponto se traduz por um par de números). Este modo associativo limita-se a alguns valores particulares e aos pontos marcados no plano referencial (DUVAL, 2011, p.98).

Ainda sobre essa questão, encontramos no PNLD 2012 observações da obra analisada, afirmado que nelas "não são tomados os devidos cuidados quando se constroem gráficos de funções. Por exemplo, com um número reduzido de valores da variável independente, induzse o aluno a considerar que é possível construir o gráfico cartesiano de uma função" (BRASIL, 2011, pg.31), ou seja, os autores não apresentam o gráfico da função numa "abordagem de 
extensão do traçado efetuado". Essa abordagem

[...] corresponde às atividades de interpolação e extrapolação aos quais se apoiam o que se denominou de aspectos produtores ou redutores das representações gráficas [...];esta abordagem de extensão não se atém mais sobre um conjunto finito de pontos marcados (a intersecção das linhas em papel milimetrado, por exemplo) como no caso da abordagem ponto a ponto; esta extensão se apoia em um conjunto infinito de pontos potenciais" (DUVAL, 2011, p. 98).

Os autores propõem análises de gráficos de uma função: crescimento ou decrescimento; máximos e mínimos; e simetrias. Em seguida, apresentam o conceito de "função afim" em meio a resoluções de situações problemas do dia a dia. Definem função afim ou "função polinomial do 10 grau" como "qualquer função $f$ de $R$ em $R$ dada por uma lei da forma $f(x)=a x+b$, em que $a$ e $b$ são números reais dados e $a \neq 0$ " (IEZZI [et al.], 2010, p.71) e função linear como um "caso particular de função afim em que $b=0$ " (IEZZI [et al.], 2010, p.71). Antes mesmo de definir coeficiente angular, coeficiente linear, raiz, crescimento, decrescimento e sinal da função, os autores propõem exercícios, apresentando gráficos para que os alunos encontrem a fórmula, ou seja, propõem a inversão de registros de partida e de chegada, dentro de uma "abordagem de interpretação global de uma representação gráfica". Nessa abordagem,

O conjunto traçado/eixos forma uma imagem que representa um objeto descrito por uma expressão algébrica. Toda modificação desta imagem, que leva a uma modificação na expressão algébrica correspondente, determina uma variável visual pertinente para a interpretação gráfica. É importante, deste modo, identificar todas as modificações pertinentes possíveis desta imagem, quer dizer, ver as modificações conjuntas da imagem e da expressão algébrica: isto significa proceder a uma análise de congruência entre dois registros de apresentação de um objeto ou de uma informação. Com esta abordagem não estamos mais na presença da associação "um 
ponto - um par de números", mas na presença da associação "variável visual de representação - unidade significativa da expressão algébrica" (DUVAL, 2011, p. 99 - grifo do autor).

No entanto, somente após estudos dos coeficientes da função afim, bem como sua raiz e seu sinal é que o aluno teria condições de fazer uma abordagem global do gráfico, o que ocorre mais adiante, quando os autores propõem estudos dos coeficientes da função afim, apresentando o termo " $a$ " como "coeficiente angular" e o termo " $b$ " como "coeficiente linear". No entanto, não fazem maiores explanações dos efeitos que estes coeficientes poderiam provocar em seus gráficos no plano cartesiano, ou seja, faltou mostrar de forma mais clara, as várias funções e suas variedades gráficas que surgem quando variamos um dos coeficientes. De posse dessa visão, os alunos passam a ter a capacidade de criar representações mentais de gráficos de qualquer função, a partir de sua expressão algébrica, e obter uma visão intuitiva de variação e correspondência. Nessa linha de pensamento, de acordo com o guia de livros didáticos de matemática (PNLD 2012), ao considerarmos uma função $f: R \rightarrow R$ que associa a um número real $x$ um número real $y$, onde $y=f(x)$, podemos tomar um número real $k \neq 0$, e formar as funções dadas por: $y=k+f(x) ; y=f(x+k) ; y=f(k x)$; $y=k f(x)$. As relações entre o gráfico da função $f$ e os gráficos das funções exemplificadas acima são ricas fontes de conexões entre as representações algébricas e gráficas das funções apresentadas.

Em particular, isso permite interpretar mudanças de variáveis como transformações geométricas no plano cartesiano. [...] é inegável que essa família de funções é importante do ponto de vista da modelagem matemática e, por isso, deveria ocupar lugar de maior destaque no ensino das funções e constituir-se em um coroamento deste ensino (BRASIL: 2011, p. $23-24)$.

Duval (2011) completa que

Uma apresentação explícita e sistemática das variações visuais significativas 
não somente centra a atenção sobre a correspondência entre a representação gráfica e expressão algébrica, mas permite encontrar diretamente a expressão algébrica das propriedades geométricas: perpendicularidade e paralelismo de duas retas, por exemplo. De fato, é suficiente praticar a abordagem experimental a mais clássica: variar uma unidade significativa na expressão, mantendo as outras constantes e ver o que se passa no outro registro (ou mudar uma variável visual mantendo as duas outras constantes e ver as modificações que acontecem na expressão). Assim, por exemplo, a oposição entre $y=x$ e $y=-x$ se articula em uma unidade de uma imagem visual e esta imagem se presta a modificações que têm contrapartida algébrica imediata (p. 103 - grifo do autor).

Contudo, o livro introduz o conteúdo com pouca explanação teórica, apresentando exemplos particulares nas atividades resolvidas de cunho aplicativo e nos exercícios de fixação, em detrimento às generalizações. Uma boa parte das questões está diretamente atrelada a construções de tabelas e gráficos. Assim, os autores não permitem aos alunos a sistematização do conceito de função, não lhes dando oportunidade da busca de suas próprias conclusões.

\section{CONSIDERAÇÕES FINAIS}

Este estudo nos permitiu analisar o tratamento que o livro didático adotado pelo professor de uma sala de aula do Ensino Médio pesquisada dá ao conceito de função. As análises feitas nos permitiu inferir que os autores do livro didático apresentam o conceito de função, de certa forma, observando alguns aspectos da transposição didática proposta por Chevallard (1991), contextualizando e dando algumas representações por meio de diagramas, tabelas e expressões algébricas. No entanto, não criam situações suficientes de conversões de registros das representações, de forma que o aluno possa relacioná-las e dar significados ao objeto matemático estudado. As atividades propostas no livro ficam aquém de tarefas que, de fato, poderiam fazer com que os alunos percebessem as variações dos gráficos com as 
devidas variações das unidades significativas na expressão algébrica correspondente.

Para definir formalmente o conceito de função, os autores do livro didático analisado começam propondo representações de função por meio de diagramas de flechas e relação entre dois conjuntos para depois trazerem a definição de função. Na análise efetuada, percebe-se que a definição proposta está basicamente centrada na teoria de conjuntos. As noções de dependência, correspondência, variáveis dependentes e independentes, um aspecto importante na construção do conceito de função, são trabalhados de forma isolada, não ficando evidente no momento da apresentação de sua definição. Não aplicam todas as regras de correspondência semiótica entre o registro da representação gráfica e o registro da expressão algébrica, atendo-se somente à passagem da expressão algébrica para a sua representação gráfica, por meio da construção ponto a ponto. De acordo com Duval (2011),

\begin{abstract}
Quando se trata de partir da representação gráfica para encontrar, por exemplo, a equação correspondente ou para utilizar o conceito de inclinação ou de direção, é esta abordagem de interpretação global que se torna necessária. A razão disto se deve ao fato de que o recurso à abordagem ponto a ponto é totalmente inoperante uma vez que tira a atenção das variáveis visuais. A prática sistemática da abordagem ponto a ponto não favorece a abordagem de interpretação global que é em geral deixada de lado no ensino uma vez que depende de análise semiótica visual e algébrica. Compreende-se porque a maioria dos alunos fica aquém de uma utilização correta das representações gráficas (p. 99 - grifo do autor).
\end{abstract}

Pode-se concluir inicialmente que o livro didático não permite ao aluno modelar situações que dão ênfase à variabilidade e não dá elementos fundamentais para a formalização do conceito de função. Sendo assim, não possibilita uma aprendizagem significativa e não proporciona uma representação mental das noções de dependência, correspondência, variáveis dependentes e independentes de uma função. 


\section{REFERÊNCIAS}

AVOLIO, J. C.; FAURY, M. Michaelis: Dicionário prático francês-português-francês. São Paulo: Melhoramentos, 2009.

BRASIL. Guia de livros didáticos: PNLD 2012: Matemática. Brasília: Ministério da Educação, Secretaria de Educação Básica, 2011.

BRASIL. Orientações curriculares para o Ensino Médio / Ciências da natureza, matemática e suas tecnologias. SEB. Brasília: Ministério da Educação, 2006. V 2. 135 p.

BOYER, C. B. História da Matemática. Tradução Gomide, E. F. São Paulo: Edgard Bluger, 1974.

CARAÇA, B. J. Conceitos Fundamentais da Matemática. Lisboa: Gradiva Publicações, 2010.

CHEVALLARD, Yves. La transpostion didactique: du savoir savant au savoir enseigné. La Pensée Sauvage Éditions: Grenoble, 1991.

DUVAL, R. Gráficos e equações: a articulação de dois registros. Revista Eletrônica de Matemática. Florianópolis (SC), v. 6, n. 2, p. 96-112, 2011.

DUVAL, R. Registros e representações semióticas e funcionamento cognitivo do pensamento. Revista Eletrônica de Educação Matemática. Florianópolis (SC), v. 7, n. 2, p. 266-297, 2012.

SILVA FILHO, Ives Gandra M. Manual esquemático de filosofia. 3ạ ed. São Paulo: LTr., 2006.

IEZZI, G. e outros. Matemática: Ciências e Aplicação. Ensino Médio. São Paulo: Saraiva, 2010.

LEITE, M. S. Contribuições de Basil Bernstein e Yves Chevallard para a discussão do conhecimento escolar. Dissertação de mestrado apresentada ao Programa de Pós-Graduação em Educação. PUC-Rio. 2004. Disponível em <http://www.maxwell.lambda.ele.pucrio.br/Buscaetds.php?strSecao=resultado\&nrSeq =5269@1>: Acesso em: 18 jul. 2012.

MENDES, Maria Helena Monteiro. 0 conceito de função: aspectos históricos e dificuldades apresentadas por alunos na transição do sendo para o terceiro grau. Dissertação de Mestrado, PUC-Rio de Janeiro, 1994.

MICHAELIS. Dicionário prático: Inglês-português-inglês. São Paulo: Melhoramentos, 2009.

OLIVEIRA, N. Conceito de função: uma abordagem do processo ensino-aprendizagem. 1997. 174 f. Dissertação de Mestrado em Ensino da Matemática. PUC - São Paulo. 1997.

YOUSCHKEVITCH. Le concept de fonction jusqu'au milieu du XIXe siècle. Em: Fragments d'histoire des Mathématiques. Brochure A.P.M.E.P. no 41, 1981, p.7-67. 